\title{
Patent Foramen Ovale Closure: Opportunity Closed in Old Patients?
}

\author{
Jong S. Kim, ${ }^{a}$ Keun-Sik Hong ${ }^{b}$ \\ aDepartment of Neurology, Asan Medical Center, University of Ulsan College of Medicine, Seoul, Korea \\ ${ }^{b}$ Department of Neurology, Inje University Ilsan Paik Hospital, Inje University College of Medicine, Goyang, Korea
}

Recent randomized trials have demonstrated the benefit of patent foramen ovale (PFO) closure for secondary stroke prevention in patients with high-risk PFO. ${ }^{1-3}$ Since these trials exclusively enrolled patients aged $\leq 60$ years, the current American Academy of Neurology guideline recommends PFO closure in stroke patients who are $<60$ years old. ${ }^{4}$ Does this mean that PFO closure should not be advised for patients $\geq 60$ years old? Importantly, although the guideline mentions an age limitation, there have been no reports of inefficiency or adverse effects of PFO closure in older patients. Previous studies excluded old patients because older patients compared with younger patients are more likely to have other undetected etiologies such as covert atrial fibrillation (AF), hidden malignancy, or aortic atheroma. ${ }^{5}$

The presence of the so-called risk of paradoxical embolism (RoPE) score has added confusion; some argue that older patients should be excluded from PFO closure because they have low RoPE scores. However, this approach does not appear to be logical because the RoPE score was primarily developed to estimate an individualized probability of the causal relation of PFO to stroke in young patients with cryptogenic stroke. ${ }^{6}$ The RoPE score is naturally low in older patients simply because they are old and tend to have vascular risk factors. Studies have shown that older patients with PFO more often develop future stroke than their young counterparts. ${ }^{7}$ Aside from the possible presence of covert AF or greater PFO sizes, older patients are more likely to have venous thrombosis and pulmonary hypertension that potentially increase the risk of PFO-related stroke.

Device Closure Versus Medical Therapy for Cryptogenic Stroke Patients With High-Risk Patent Foramen Ovale (DEFENSE-PFO) is one of the major randomized trials that showed the benefit of PFO closure in stroke patients with high-risk PFO. In contrast to the other studies, this trial had no age limitations. In this issue of the Journal of Stroke, Kwon et al. ${ }^{8}$ presented the subgroup analysis data of DEFENSE-PFO, which included the benefit of PFO in the patients with aged $\geq 60$ years. Of patients randomized to medical treatment, the 2-year risk of ischemic stroke or transient ischemic stroke (TIA) in the old ( $\geq 60$ years) patients was quite high as $24.6 \%$, while it was $5.8 \%$ in the young ( $<60$ years) patients. Most recurrent events were ischemic strokes, and all the ischemic strokes were considered as PFO-related strokes. There was no recurrent ischemic stroke or TIA in patients who received PFO closure. Accordingly, the benefit of PFO closure looks greater in patients $\geq 60$ years than in those $<60$ years despite no clear evidence of treatment-by-age interaction. In this study, the higher event rate in elderly patients was not attributed to characteristics of PFO features because the trial initially enrolled patients with highrisk PFO only.

The results of this study should be interpreted with caution because of the small outcome events and an inadequate statistical power. Thus, the age limitation in the guidelines will not be changed until future large randomized trials confirm this preliminary result. Nevertheless, this paper intriguingly suggests that PFO closure may be considered in carefully selected old patients who have high-risk PFO.

\section{References}

1. Carroll JD, Saver JL, Thaler DE, Smalling RW, Berry S, MacDonald $L A$, et al. Closure of patent foramen ovale versus medical therapy after cryptogenic stroke. N Engl J Med 2013;368:10921100. 
2. Mas JL, Derumeaux G, Guillon B, Massardier E, Hosseini $H_{\text {, }}$ Mechtouff $L$, et al. Patent foramen ovale closure or anticoagulation vs. antiplatelets after stroke. N Engl J Med 2017;377: 1011-1021.

3. Søndergaard L, Kasner SE, Rhodes JF, Andersen G, Iversen HK, Nielsen-Kudsk JE, et al. Patent foramen ovale closure or antiplatelet therapy for cryptogenic stroke. N Eng/ J Med 2017;377: 1033-1042.

4. Messé SR, Gronseth GS, Kent DM, Kizer JR, Homma S, Rosterman $L$, et al. Practice advisory update summary: patent foramen ovale and secondary stroke prevention: report of the Guideline Subcommittee of the American Academy of Neurology. Neurology 2020;94:876-885.

5. Köhrmann M, Schellinger PD, Tsivgoulis G, Steiner T. Patent foramen ovale: story closed? J Stroke 2019;21:23-30.

6. Kent DM, Ruthazer R, Weimar C, Mas JL, Serena J, Homma S, et al. An index to identify stroke-related vs incidental patent foramen ovale in cryptogenic stroke. Neurology 2013;81:619-625.

7. Mazzucco S, Li L, Rothwell PM. Prognosis of cryptogenic stroke with patent foramen ovale at older ages and implications for trials: a population-based study and systematic review. JAMA Neurol 2020;77:1279-1287.

8. Kwon H, Lee PH, Song JK, Kwon SU, Kang DW, Kim JS. Patent foramen ovale closure in old stroke patients: a subgroup analysis of the DEFENSE-PFO trial. J Stroke 2021;23:289-292.

Correspondence: Jong S. Kim

Department of Neurology, Asan Medical Center, University of Ulsan College of Medicine, 88 Olympic-ro 43-gil, Songpa-gu, Seoul 05505, Korea Tel: +82-2-3010-3440

Fax: +82-2-474-4691

E-mail: jongskim@amc.seoul.kr https://orcid.org/0000-0002-3999-4992

Received: May 3, 2021

Revised: May 10, 2021

Accepted: May 10, 2021

The authors have no financial conflicts of interest. 